\title{
FAKTOR-FAKTOR YANG BERHUBUNGAN DENGAN PERKEMBANGAN MOTORIK HALUS ANAK BATITA (TODDLER) DI POSYANDU ANGGREK MERAH RW 08 CILOLOHAN KELURAHAN KAHURIPAN KOTA TASIKMALAYA
}

\author{
Fitri Meilani $^{1}$, Ali Musthofa ${ }^{2}$ \\ ${ }^{1,2}$ Program Studi Sarjana Keperawatan, Sekolah Tinggi Ilmu Kesehatan Dharma Husada Bandung \\ 1) fitrimeilani012@gmail.com \\ 2) alimusthofa@stikesdhb.ac.id
}

\begin{abstract}
ABSTRAK
Secara statistik sekitar 3\% anak usia 1-3 tahun di Indonesia tidak bisa mencapai perkembangan motorik halusnyanya tepat waktu. Penelitian bertujuan untuk menganalisis faktor-faktor yang berhubungan dengan perkembangan motorik halus pada anak batita di Posyandu Anggrek Merah RW 08 Cilolohan Kelurahan Kahuripan Kota Tasikmalaya. Jenis penelitian deskriptif kuantitatif dengan penelitian analitik observasional dan pendekatan Cross Sectional. Populasi penelitian adalah anak batita dengan jumlah 48 anak. Teknik sampling yang digunakan yaitu Total Sampling. Instrumen penelitian menggunakan kuesioner dan format Denver II. Hasil penelitian menunjukkan ibu-ibu dari batita memiliki riwayat pendidikan rendah (SD-SMP) 47,92\%, responden batita laki-laki 52,1\%, perempuan $47,9 \%$, riwayat tidak ASI Ekslusif 54,2\%, status gizi batita normal 91,7\%, pola asuh positif $68,8 \%$, batita stimulasi baik maupun stimulasi buruk $50 \%$, dan batita dengan perkembangan motorik halus normal 95,8\%. Hasil analisa uji Chi-Square didapatkan faktor yang berhubungan dengan perkembangan motorik halus anak batita yaitu faktor status gizi $(p=0.015<0.05)$. Sedangkan antara faktor pendidikan ibu, jenis kelamin anak, pemberian ASI Ekslusif, pola asuh orang tua dan stimulasi tidak ada hubungan dengan perkembangan motorik halus pada anak batita. Posyandu diharapkan dapat melakukan pendidikan kesehatan terhadap ibu mengenai pentingnya pemantauan perkembangan motorik anak dan meningkatkan pelayanan kesehatan optimal dalam pemulihan status gizi anak batita sehingga perkembangan motorik halus anak dapat berkembang sesuai tahapan usianya.
\end{abstract}

Kata Kunci : ASI Ekslusif, Batita (Toddler), Jenis Kelamin Anak, Motorik Halus. Pendidikan Ibu, Perkembangan, Pola Asuh, Status Gizi, Stimulasi

\section{LATAR BELAKANG}

Perkembangan adalah bertambahnya kemampuan dan keterampilan dalam struktur fungsi tubuh yang lebih kompleks dalam pola yang teratur dan dapat diramalkan, sebagai hasil proses pematangan. Perkembangan menyangkut adanya proses diferensiasi dari sel-sel tubuh, jaringan tubuh, organ-organ, dan sistem organ yang berkembangan sedemikian rupa sehingga masing-masing dapat memenuhi fungsinya. Termasuk juga perkembangan emosi, intelektual, dan tingkah laku sebagai hasil interaksi dengan lingkungannya. Perkembangan merupakan perubahan yang bersifat progresif, terarah dan terpadu atau koheren. Progresif mengandung arti bahwa terdapat hubungan yang pasti antara perubahan yang terjadi pada saat ini, sebelumnya dan berikutnya. Tahapan perkembangan ini terdiri dari bahasa, motorik kasar dan motorik halus serta personal sosial (Soetjiningsih, 2015). 
Motorik halus adalah pergerakan yang melibatkan otot-otot halus pada tangan dan jari yang terkoordinasi dengan penglihatan. Pada anak, perkembangan motorik halus harus selalu dipantau dan dirangsang, sehingga anak dapat berkembang dengan optimal. Perkembangan motorik halus pada anak batita (Toddler) merupakan suatu hal yang penting bagi perkembangan anak. Anak membutuhkan belajar menggunakan tangan dengan baik agar dapat menggerakkan mainan dan untuk keterampilan hidup seperti makan dan memakai pakaian sendiri. Keterampilan motorik halus melibatkan gerakan yang diatur secara halus. Gangguan pada perkembangan motorik halus biasanya menyebabkan anakanak mengalami kesulitan belajar (Santrock, 2007).

Perkembangan motorik halus anak pada 3 tahun pertama kehidupan begitu pesat, dan yang berperan utama dalam pengasuhan bayi adalah ibu. Ibu mempunyai kedekatan yang lebih dalam terhadap anak karena ibu yang melahirkan dan menyusui. Keterampilan motorik halus anak usia toddler harus dirangsang, dilatih, dan dikembangkan setiap saat dengan berbagai aktivitas atau permainan yang membuatnya terhibur. Perkembangan anak batita (Toddler) dipengaruhi oleh faktor hereditas dan lingkungan. Faktor lingkungan, seperti lingkungan keluarga, sekolah, kelompok teman sebaya dan media masa. Lingkungan keluarga dipandang sebagai faktor penentu bagi perkembangan anak, dimana faktor penentu utama di lingkungan keluarga adalah orang tua (Yusuf, 2011). Pola pengasuhan yang diterapkan oleh ibu terhadap anak bergantung pada pendidikan dan pengalaman ibu. Ibu yang memiliki pendidikan tinggi akan mudah menerima sumber informasi. Pencarian informasi mengenai pertumbuhan dan perkembangan anak pun semakin sering terjadi sehingga ibu yang berpendidikan tinggi cenderung lebih sering menstimulasi (Yuniarti, 2015).

Dalam perkembangan anak batita (Toddler) terdapat masa kritis, dimana diperlukan rangsangan/stimulasi yang berguna agar potensi yang ada bisa berkembang, sehingga perlu mendapat perhatian. Perkembangan psiko-sosial sangat dipengaruhi lingkungan dan interaksi antara anak dengan orang tuanya/orang dewasa lainnya (Soetjiningsih, 2015). Faktor kebutuhan stimulasi atau rangsangan terhadap anak untuk memperkenalkan suatu pengetahuan ataupun keterampilan baru ternyata sangat penting dalam peningkatan kecerdasan anak. Salah satu bentuk kecerdasan yang harus dikembangkan ialah stimulasi motorik. Apabila pada usia tertentu anak belum bisa melakukan motorik halus, maka anak telah mengalami keterlambatan. Oleh sebab itu stimulasi motorik harus dikembangkan karena anak yang mendapat stimulasi terarah dan teratur akan lebih cepat berkembang dibandingkan dengan anak yang tidak/kurang mendapatkan stimulasi (Tedjasaputra, 2006). Dari hasil penelitian sebelumnya menunjukkan terdapat hubungan positif yang kuat antara stimulasi tumbuh 
kembang dengan perkembangan anak usia 1-3 tahun (Suci H\&Lestari, 2016)

Dari hasil wawancara dari Bidan Kahuripan didapatkan data bahwa di daerah binaan Puskesmas Kahuripan terdapat 3 orang anak batita (Toddler) yang mengalami gangguan pertumbuhan dan perkembangan yaitu anak dengan down syndrome, autisme, dan retardasi mental. Namun salah satu dari ketiga anaktersebut terutama dari pihak keluarga sulit untuk dilakukan intervensi agar keluarga membawa anak tersebut dibawa ke Posyandu.

Hasil observasi pada tanggal 12 September 2019 di Posyandu Anggrek Merah RW 08, hasil pengukuran perkembangan menggunakan Denver Development Screening Test II (DDST II) dari 10 anak batita (Toddler) teridentifikasi 3 anak yang aspek perkembangan motorik halusnya tidak tercapai berdasarkan tahapan perkembangan usianya seperti salah satunya pada saat peneliti meneliti anak berumur 24 bulan tersebut menggambar garis, anak tidak bisa melakukan sesuai dengan perintah, untuk anak kedua berumur 12 bulan pada saat peneliti meletakkan pensil tersebut di tangan bayi dengan mudahnya peneliti mengambil pensil tersebut dikarenakan genggaman bayi tidak kuat, dan untuk anak ketiga berumur 22 bulan pada saat anak diberikan gelas yang terisi air anak tersebut meminumnya tetapi airnya tumpah sehingga dapat di tarik masalah bahwa kemampuan motorik halus anak batita(Toddler) di daerah tersebut menurut tingkat pencapaian perkembangan anak khususnya usia $12-36$ bulan seharusnya sudah dapat mengkoordinasikan mata dan tangan untuk melakukan gerakan-gerakan yang rumit.

Di Posyandu tersebut sering mendapatkan suatu percakapan para ibu rumah tangga yang membandingkan masing masing kepintaran anaknya dengan anak batita lain atau masih banyak ibu rumah tangga yang mengeluh mengenai perkembangan anaknya. Jika ini dibiarkan berlanjut, orang tua akan menjadi stress memikirkan keadaan anak yang masih sangat lucu dan menggemaskannya itu. Anak batita (Toddler) merupakan kelompok yang sangat perlu diperhatikan sebab sampai saat ini pihak kader posyandu dan tenaga kesehatan yang berada di wilayah tersebut belum sepenuhnya melaksanakan deteksi perkembangan masing-masing anak yang datang ke posyandu tersebut

\section{METODE PENELITIAN}

Jenis Penelitian ini merupakan penelitian analitik,observasional yaitu menganalisa faktor-faktor yang berhubungan dengan perkembangan motorik halus anak batita (Toddler) di Posyandu Anggrek Merah RW 08 Cilolohan Kelurahan Kahuripan Kota Tasikmalaya

Populasi dalam penelitian ini adalah anak batita (Toddler) usia 1-3 tahun di daerah RW 08 Cilolohan Kelurahan Kahuripan Kota Tasikmalaya dengan jumlah populasi 48 orang anak batita yang sehat dan tidak cacat fisik atau mental. 
Teknik sampling yang di gunakan peneliti yaitu Total Sampling, yaitu seluruh populasi diambil untuk dijadikan sampel. Sampel pada penelitian ini adalah anak batita (Toddler) usia 1-3 tahun di Posyandu Anggrek Merah RW 08 Cilolohan Kelurahan Kahuripan Kota Tasikmalaya dengan jumlah 48 orang.

Terdapat dua variabel penelitian yaitu variabel independent dan variabel dependent. Variabel indipendent adalah Pendidikan ibu, Jenis kelamin, Pemberian ASI Eksklusif, Pola Asuh Orang Tua, Status gizi, Stimulasi. Variabel dependent nya adalah Perkembangan motorik halus anak batita (Toddler).

Instrumen pengumpulan data untuk memperoleh data faktor-faktor yang berhubungan dengan perkembangan motorik halus anak batita (Toddler) berupa kuesioner yang berisi pertanyaan tentang identitas inisial responden dan orang tua serta kuesioner pola asuh orang tua, serta menggunakan format denver. Sebelumnya instrumen dilakukan uji validitas dengan hasil valid dan reliabel.

Peneliti melakukan pengumpulan data secara formal kepada responden di Posyandu Anggrek Merak RW 08 Cilolohan Kota Tasikmalaya dan mengarahkan untuk menjawab dengan jujur di kuesioner yang sudah diberikan peneliti. Sebelumnya peneliti membuat informed concent (persetujuan) terlebih dahulu kepada responden bahwa responden bersedia akan dilakukan penelitian, setelah responden setuju baru peneliti membagikan kuesioner tersebut yang berisi daftar pertanyaan yang diajukan secara tertulis.
Yang mengisi kuesioner itu adalah responden yang mana daftar pertanyaan tersebut sudah disusun sebelum memberikan kuesioner kepada responden. Kemudian dalam jangka waktu tertentu kuesioner tersebut diambil kembali oleh peneliti untuk dikumpulkan data yang sudah didapat.

Setelah melalui proses pengolahan data, selanjutnya peneliti melakukan analisis untuk mendapatkan jawaban atau informasi terkait penelitian yang dilakukan. Analisa data bertujuan untuk memperoleh gambaran hasil penelitian yang telah dirumuskan dalam tujuan penelitian, analisa data dapat membuktikan hipotesis penelitian yang telah dirumuskan, analisa data ini menggunakan program komputer melalui tahap univariat dan analisis bivariat dengan menggunakan uji Chi-Square.

\section{HASIL PENELITIAN}

\section{a. Hasil}

\section{1) Analisa hubungan antara faktor pendidikan ibu dengan perkembangan motorik halus anak batita (Toddler) di Posyandu Anggrek Merah RW 08 Cilolohan $(\mathrm{N}=48)$}

Ibu dengan pendidikan tinggi memiliki anak batita (Toddler) dengan perkembangan motorik halus normal sebanyak 22 orang $(95,7 \%)$ dan perkembangan motorik halus suspek sebanyak 1 orang $(4,3 \%)$ sedangkan ibu dengan pendidikan dasar memiliki anak batita (Toddler) dengan perkembangan motorik halusnormal sebanyak 23 orang (92\%) dan perkembangan motorik halus suspek sebanyak 2 orang $(8 \%)$, 
Hasil analisis uji Chi Square menunjukkan $\mathrm{P}=0,532$ (sig $>0,05)$, maka $\mathrm{H} 0$ diterima artinya tidak ada hubungan antara faktor pendidikan ibu dengan perkembangan motorik halus anak batita (Toddler) di Posyandu Anggrek Merah RW 08 Cilolohan.

2) Analisa hubungan antara faktor jenis kelamin anak dengan perkembangan motorik halus anak batita (Toddler) di Posyandu Anggrek Merah RW 08 Cilolohan $(\mathrm{N}=48)$

Batita (Toddler) dengan jenis kelamin laki-laki memiliki perkembangan motorik halus normal sebanyak 25 orang $(96,2 \%)$ dan perkembangan motorik halus suspek sebanyak 1 orang $(3,8 \%)$ sedangkananak batita (Toddler) dengan jenis kelamin perempuan memiliki perkembangan motorik halus normal sebanyak 20 orang $(90,9 \%)$ dan memiliki perkembangan motorik halus suspek sebanyak 2 orang $(9,1 \%)$.

Hasil analisis uji Chi Square menunjukkan $\mathrm{P}=0,436$ (sig $>0,05$ ), maka $\mathrm{H0}$ diterima artinya tidak ada hubungan antara faktor jenis kelamin anak dengan perkembangan motorik halus anak batita (Toddler) di Posyandu Anggrek Merah RW 08 Cilolohan

\section{3) Analisa Hubungan antara Faktor} Pemberian Asi Ekslusif dengan Perkembangan Motorik Halus Anak Batita (Toddler) Di Posyandu Anggrek Merah RW 08 Cilolohan $(\mathrm{N}=48)$

Batita (Toddler) yang diberi ASI Ekslusif memiliki perkembangan motorik halus motorik halus normal sebanyak 21 orang $(95,5 \%)$ dan yang memiliki perkembanganmotorik halus Jurnal Penelitian Kesehatan STIKes Dharma Husada Bandung suspek sebanyak 1 orang (4,5\%) sedangkan anak batita (Toddler) yang tidak diberi ASI Ekslusif memiliki perkembangan motorik halus normal sebanyak 24 orang $(92,3 \%)$ dan yang memiliki perkembangan motorik halus suspek sebanyak 2 orang $(7,7 \%)$.

Hasil analisis uji Chi Square menunjukkan $\mathrm{P}=0,564$ (sig $>0,05)$, maka $\mathrm{H} 0$ diterima artinya tidak ada hubungan antara faktor pemberian ASI Ekslusif dengan perkembangan motorik halus anak batita (Toddler) di Posyandu Anggrek Merah RW 08 Cilolohan

4) Analisa hubungan antara faktor status gizi anak dengan perkembangan motorik halus anak batita (Toddler) di Posyandu Anggrek Merah RW 08 Cilolohan (N=48)

batita (Toddler) dengan status gizi normal memiliki perkembangan motorik halus normal sebanyak 43 orang $(97,7 \%)$ dan perkembangan motorik halus suspek sebanyak 1 orang $(2,3 \%)$ sedangkan anak batita (Toddler) dengan status gizi tidak normal memiliki perkembangan motorik halus normal sebanyak 2 orang (50\%) dan perkembangan motorik halus suspek (meragukan) sebanyak 2 orang (50\%)

Hasil analisis uji Chi Square menunjukkan $\mathrm{P}=0,015$ (sig<0,05), maka H0 ditolak artinya ada hubungan antara faktor status gizi anak dengan perkembangan motorik halus anak batita (Toddler) di Posyandu Anggrek Merah RW 08 Cilolohan. 
5) Analisa hubungan antara faktor pola asuh orangtua dengan perkembangan motorik halus anak batita (Toddler) di Posyandu Anggrek Merah RW 08 Cilolohan $(\mathrm{N}=48)$

Batita (Toddler) dengan pola asuh yang positif memiliki perkembangan motorik halus normal sebanyak 30 orang $(96,8 \%)$ dan yang memiliki perkembangan motorik halus suspek sebanyak 1 orang $(3,2 \%)$ sedangkan anak batita (Toddler) dengan pola asuh negatif memiliki perkembangan motorik halus normal sebanyak 15 orang $(88,2 \%)$ dan yang memiliki perkembangan motorik halus suspek sebanyak 2 orang $(11,8 \%)$

Hasil analisis uji Chi Square menunjukkan $\mathrm{P}=0,283$ (sig>0,05), maka $\mathrm{H} 0$ diterima artinya tidak ada hubungan antara faktor pola asuh orang tua dengan perkembangan motorik halus anak batita (Toddler) di Posyandu Anggrek Merah RW 08 Cilolohan.

6) Analisa hubungan antara faktor stimulasi dengan perkembangan motorik halus anak batita (Toddler) di Posyandu Anggrek Merah RW 08 Cilolohan $(\mathrm{N}=48)$

Batita (Toddler) dengan stimulasi baik memiliki perkembangan motorik halus normal sebanyak 22 orang $(91,7 \%)$ dan anak batita (Toddler) dengan perkembangan motorik halus suspek sebanyak 2 orang $(8,3 \%)$ sedangkan anak batita (Toddler) dengan stimulasi buruk memiliki perkembangan motorik halus normal sebanyak 23 orang $(95,8 \%)$ dan anak batita (Toddler) dengan perkembangan motorik halus suspek sebanyak 1 orang $(4,2 \%)$
Hasil analisis uji Chi Square menunjukkan $\mathrm{P}=0,500 \quad(\mathrm{sig}>0,05)$ maka $\mathrm{H} 0$ diterima artinya tidak ada hubungan antara faktor stimulasi dengan perkembangan motorik halus anak batita (Toddler) di Posyandu Anggrek Merah RW 08 Cilolohan.

\section{b. Pembahasan}

1) Hubungan faktor pendidikan ibu dengan perkembangan motorik halus anak batita (Toddler)

Hasil analisa bivariat faktor pendidikan ibu dengan perkembangan motorik halus anak batita (Toddler) di Posyandu Anggrek Merah RW 08 Cilolohan diperoleh hasil $p$ value $=0,532$. Hal ini menunjukkan bahwa tidak ada hubungan antara faktor pendidikan ibu dengan perkembangan motorik halus anak batita (Toddler) di Posyandu Anggrek Merah RW 08 Cilolohan.

Rendahnya tingkat pendidikan ibu menyebabkan rendahnya pengetahuan ibu khususnya dalam menerima infomasi mengenai perkembangan anak. Selanjutnya rendahnya tingkat pendidikan menyebabkan pula rendahnya pemahaman terhadap apa yang dibutuhkan dalam perkembangan optimal anak terutama mengenai motorik halus anak (Depkes, 2006). Penyebab dari tidak ada hubungan yang signifikan antara pengaruh faktor pendidikan ibu dengan perkembangan motorik halus anak batita (Toddler) mungkin bisa disebabkan oleh bahwa pengetahuan bisa didapat tidak hanya saat dibangku sekolah saja atau di perkuliahan. Seorang ibu bisa mendapatkan 
pemahaman dan pengetahuan mengenai perkembangan anak dari beberapa media yang mudah diakses seperti media televisi, radio, surat kabar, majalah parenting dan atau media internet atau ibu yang rajin bisa mendapatkan informasi mengenai perkembangan anak dengan berkonsultasi dengan dokter anak, bidan atau perawat setempat mengenai solusi perkembangan anak terutama dalam meningkatkan kemampuan motorik halus anak.

Hal ini sejalan dengan hasil penelitian yang dilakukan oleh Kusumaningtyas \& Wayanti (2016) bahwa tidak ada pengaruh faktor pendidikan ibu dengan perkembangan motorik halus anak usia 3-4 tahun

\section{2) Hubungan faktor jenis kelamin anak dengan perkembangan motorik halus anak batita (Toddler)}

Hasil analisa bivariat faktor jenis kelamin anak dengan perkembangan motorik halus anak batita (Toddler )di Posyandu Anggrek Merah RW 08 Cilolohan diperoleh hasil $p$ value $=0,436$. Hal ini menunjukkan bahwa tidak ada hubungan antara faktor jenis kelamin anak dengan perkembangan motorik halus anak batita (Toddler) di Posyandu Anggrek Merah RW 08 Cilolohan.

Dilihat dari hasil karakteristik jenis kelamin ini antara jenis kelamin laki-laki dan perempuan tidak menunjukkan adanya perbedaan yang signifikan terhadap perkembangan motorik halus anak keduanya bisa mengalami keterlambatan perkembangan motorik halus yaitu dari hasil menunjukkan bahwa ada 3 orang anak yang mengalami keterlambatan perkembangan suspek (1 orang laki-laki dan 2 orang perempuan) dari jumlah keseluruhan anak batita 48 orang sehingga bertentangan dengan yang dikemukakan oleh Yuniarti (2015) bahwa anak perempuan lebih matang dalam tingkat motorik halusnya dibandingkan dengan anak laki-laki

\section{3) Hubungan faktor pemberian ASI Eksklusif dengan perkembangan motorik halus anak batita (Toddler)}

Hasil analisa bivariat faktor pemberian ASI Eksklusif dengan perkembangan motorik halus anak batita (Toddler) di Posyandu Anggrek Merah RW 08 Cilolohan diperoleh hasil $p$-value $=0,564$. Dari hasil tersebut menunjukkan bahwa tidak ada hubungan antara faktor pemberian ASI Ekslusif dengan perkembangan motorik halus anak batita (Toddler) di Posyandu Anggrek Merah RW 08 Cilolohan. Untuk mencapai pertumbuhan, perkembangan dan kesehatan yang optimal anak harus diberi ASI eksklusif selama 6 bulan pertama, selanjutnya untuk kecukupan nutrisi anak harus mulai diberikan makanan pendamping ASI yang cukup dan aman dengan pemberian ASI tetap dilanjutkan sampai usia dua tahun atau lebih.

Menurut Yusari (2016), ASI adalah makanan satu-satunya yang paling sempurna untuk menjamin tumbuh kembang anak pada enam bulan pertama, anak akan mendapatkan perkembangan jasmani, emosi maupun spiritual yang baik dalam kehidupannya. ASI Ekslusif sangat penting dalam menentukan 
perkembangan motorik anak.manfaat pemberian ASI Eksklusif yang begitu besar baik untuk ibu maupun anak sehingga anak dapat terhindar dan tidak mudah terserang dari berbagai macam penyakit yang terkadang dapat menyebabkan kesakitan dan kematian pada anak (Roesli, 2010). Akan tetapi hasil penelitian ini tidak menunjukkan adanya pengaruh antara ASI Ekslusif dengan perkembangan motorik halus anak, hal ini sejalan dengan hasil penelitian yang dilakukan oleh Novita Sari (2011) bahwa tidak terdapat hubungan signifikan antara pemberian ASI Eksklusif dengan perkembangan motorik anak usia $6-8$ bulan

\section{4) Hubungan faktor status gizi anak dengan perkembangan motorik halus anak batita (Toddler)}

Hasil analisa bivariat faktor status gizi anak dengan perkembangan motorik halus anak batita (Toddler) di Posyandu Anggrek Merah RW 08 Cilolohan diperoleh hasil $p$ value $=0.015$. Hal ini menunjukkan bahwa ada hubungan antara faktor status gizi anak dengan perkembangan motorik halus anak batita (Toddler) di Posyandu Anggrek Merah RW 08 Cilolohan. Status gizi anak sangat penting bagi anak dalam masa pertumbuhan dan perkembangan.Pada masa perkembangan nutrisi sangat diperlukan dalam peningkatan IQ anak serta perkembangan motorik halusnya (Yuniarti, 2015). Oleh karena itu status gizi yang buruk akan mengganggu proses perkembangan anak batita, sehingga bahwa terdapat kaitan antara status gizi pada anak usia dini dengan perkembangan motorik. Hal ini sejalan dengan hasil penelitian yang dilakukan oleh Khusna (2015) bahwa hubungan status gizi dengan perkembangan motorik halus pada anak usia 1-3 tahun

\section{5) Hubungan Pengaruh faktor pola asuh orang tua dengan perkembangan motorik halus anak batita (Toddler)}

Hasil analisa bivariat faktor pola asuh orang tua dengan perkembangan motorik halus anak batita (Toddler) di Posyandu Anggrek Merah RW 08 Cilolohan diperoleh hasil $p$-value $=0,283$. Hal ini menunjukkan bahwa tidak ada hubungan antara faktor pola asuh orang tua dengan perkembangan motorik halus anak batita (Toddler) di Posyandu Anggrek Merah RW 08 Cilolohan.

Menurut Edward (2006) menyatakan bahwa pola pengasuhan orang tua sangat dipengaruhi oleh lingkungan sekitar, maka tidak mustahil jika lingkungan juga ikut mewarnai pola-pola pengasuhan yang diberikan oleh ibu kepada anak-anaknya. Jaringan sosial pun bisa mempengaruhi salah satu interpersonal dalam menentukan pola asuh terhadap perkembangan anak (Shanker\&Diamond, 2008). Sehingga memungkinkan suatu komunitas terpengaruhi dan berdampak pada pola asuh anak. Hal ini sejalan dengan hasil penelitian yang dilakukan oleh Yulita (2014) bahwa tidak terdapat hubungan antara pola asuh orang tua dengan perkembangan balita. 
6) Hubungan faktor stimulasi dengan perkembangan motorik halus anak batita (Toddler)

Hasil analisa bivariat faktor stimulasi dengan perkembangan motorik halus anak batita (Toddler) di Posyandu Anggrek Merah RW 08 Cilolohan diperoleh hasil $p$ value $=0,500$. Hal ini menunjukkan bahwa tidak ada hubungan antara faktor stimulasi dengan perkembangan motorik halus anak batita (Toddler) di Posyandu Anggrek Merah RW 08 Cilolohan. Dari hasil tersebut dapat dikatakan bahwa pemberian stimulasi adalah kegiatan merangsang kemampuan dasar anak umur 0-6 tahun agar anak tumbuh dan berkembang secara optimal (Depkes, 2007). Menurut WHO (2006), seorang anak batita harus mendapat stimulasi positif dari lingkungannya. Banyak orang tua yang begitu bersemangat memberikan stimulasi untuk anak batitanya.Akibatnya malah overstimulasi. Overstimulasi yang dilakukan terus-menerus tentu memberikan efek yang tidak menguntungkan bagi batita, seperti: emosi negatif, kemampuan belajar menurun, dan menolak. Sedangkan bila kehilangan pengasuhan yang baik, misalnya pendidikan orang tua yang rendah berbagai hal lainnya akan sangat mempengaruhi kesehatan fisik dan psikologinya. Hal ini disesuaikan dengan tingkat pendidikan ibu yang rendah (SDSMP) yang berada di wilayah posyandu Anggrek Merah RW 08 Cilolohan dan sejalan dengan hasil penelitian Hal ini bertentangan dengan hasil penelitian yang dilakukan oleh Suci \& Lestari (2016) bahwa terdapat Jurnal Penelitian Kesehatan STIKes Dharma Husada Bandung pengaruh pemberian stimulasi pada perkembangan anak usia 12-36 bulan

\section{DAFTAR PUSTAKA}

Aticeh, dkk. (2015). Pengetahuan Kader Meningkatkan Motivasi Dalam Melakukan Deteksi Dini Tumbuh Kembang Balita http://ejurnal.poltekkesjakarta3.ac.id/inde x.php/JITEK/article/view/95 (di unduh pada tanggal 10 Maret 2016)

Arikunto, Suharsimi. (2006). Manajemen Penelitian. Jakarta: Rineka Cipta

Bararah, V, F. (2010). Penyebab Anak Telat Berkembang. http://health.detik.com. Diakses pada tanggal 12 Maret 2017

Blair, C. \& Diamond, A. (2008). Biological Processes in Prevention and Intervention : The Promotion of Self Regulationas a mens of Preventing School Failure. Development and Psychopathology. Vol. 20

Dahlan, S. (2014). Statistik Untuk Kedokteran dan Kesehatan. Jakarta: Epidemiologi Indonesia

Departemen Kesehatan RI. (2012). Jumlah Anak Balita 2012. Tersedia dalam http://www.diskes.jabarprov.go.id. Diakses pada tanggal 28 November 2016

Hidayat, Aziz. (2014). Metode Penelitian Kebidanan Teknik Analisis Data. Jakarta: Salemba Medika

Hurlock, E.B. (1997). Psikologi Perkembangan Suatu pendekatan Sepanjang Rentang Kehidupan. Edisi 5 : Jakarta : Erlangga IDAI. 2010. Ikatan Dokter Anak Indonesia

Kemenkes RI. (2010). Instrumen Stimulasi, Deteksi dan Intervensi Dini Tumbuh Kembang Anak. Jakarta

Kyle, Tery \& Carman,S. (2015). Buku Ajar Keperawatan Pediatrik. Volume I, Edisi 2. Jakarta : EGC 
Maria, N. F \& Adriani, M. (2009) Hubungan Pola Asuh, Asih, Asah Dengan Tumbuh Kembang Balita Usia 1-3 Tahun. Jurnal FKIK. UNS Diakses pada tanggal 12 Maret 2017

Nursalam. (2010). Konsep dan Penerapan Metodologi Penelitian Ilmu Keperawatan. Jakarta : Salemba Medika

Riyanto, A. (2011). Pengolahan dan Analisis Data Kesehatan. Yogyakarta: Nuha Medika

Roesli, U. (2010). Inisiasi Menyusui Dini Plus ASI Eksklusif. Jakarta : Pustaka Bunda.

Penumping Surakarta. Jurnal Kesehatan Universitas Muhamadiyah Surakarta

Rumah Sakit Umum Darmo Surabaya. 2012. Data Statistik Pasien Anak. Surabaya.

Soetjiningsih, (2015). Tumbuh Kembang Anak. Jakarta: EGC

Tedjasaputra, M. (2006). Perkembangan Anak Usia Dini. Jakarta.

UNICEF, 2010. Angka Kejadian Pertumbuhan dan Perkembangan Anak Balita tahun 2010, tersedia dalam http://www.academia.edu. Diakses tanggal 28 November 2016

WHO \& UNICEF, (2006) Regional child survival strategy: Acceleratedand sustained action to wards MDG 4. WHO Press. World Health Organization, Geneva, Switzerland.

Wong, D. L., Eaton, MH., Wilson, D., Winkelstein, ML., Schwartz, p.(2008). Buku ajar keperawatan pediatrik.Terjemahan oleh Agus Sutarna \& Neti : Jakarta: EGC

Yuniarti, Sri. (2015). Asuhan Tumbuh Kembang Neonatus Bayi-Balita dan Anak Pra Sekolah. Bandung: PT Refika Aditama

Jurnal Penelitian Kesehatan STIKes Dharma Husada Bandung
Yusari Asih, H. R. (2016). Buku Ajar Asuhan Kebidanan Nifas dan Menyusui. Jakarta: CV. Trans Info Media 